\title{
Low toxicity and high surface activity of sophorolipids from Starmerella bombicola in aquatic species: A preliminary study
}

\begin{tabular}{|c|c|}
\hline Paper received: 27.03.2018 & Revised received: 12.11.2018 \\
\hline
\end{tabular}

\begin{abstract}
Authors Info
W. Kumano, K. Namakoshi, M. Araki, Y. Oda, A. Ueda, and Y. Hirata*

Biochemical Laboratory, Saraya Co. Ltd., Osaka- 582-0028, Japan

*Corresponding Author Email : hirata@saraya.com
\end{abstract}

\section{Edited by \\ Dr. V.K. Tiwari}

\section{Abstract}

Aim : This study was carried out to evaluate aquatic toxicity and surface activity of sophorolipids extracted from yeast Starmerella bombicola.

Methodology : The half maximal effective concentration $\left(E C_{50}\right)$ values of sophorolipids were determined in three aquatic species, and the surface activity of sophorolipids in aqueous solutions was examined at $\mathrm{EC}_{50}$ concentration.

Results : The $\mathrm{EC}_{50}$ of sophorolipid surfactant $>473 \mathrm{mg} \mathrm{I}^{-1}$ was found in alga Pseudokirchneriella subcapitata, a median lethal concentration $\left(\mathrm{LC}_{50}\right)$ of $64.8 \mathrm{mg} \mathrm{l}^{-1}$ in fish Oryzias latipes, whereas a high $\mathrm{EC}_{50}$ of $48.2 \mathrm{mg} \mathrm{l}^{-1}$ was noted in crustacean Daphnia magna, respectively. Sophorolipids effectively reduced the aquatic surface tension to $39 \mathrm{mN} \mathrm{m}^{-1}$ in 0 . latipes and to $41 \mathrm{mN} \mathrm{m}^{-1}$ in D. magna.

Interpretation : These results show that
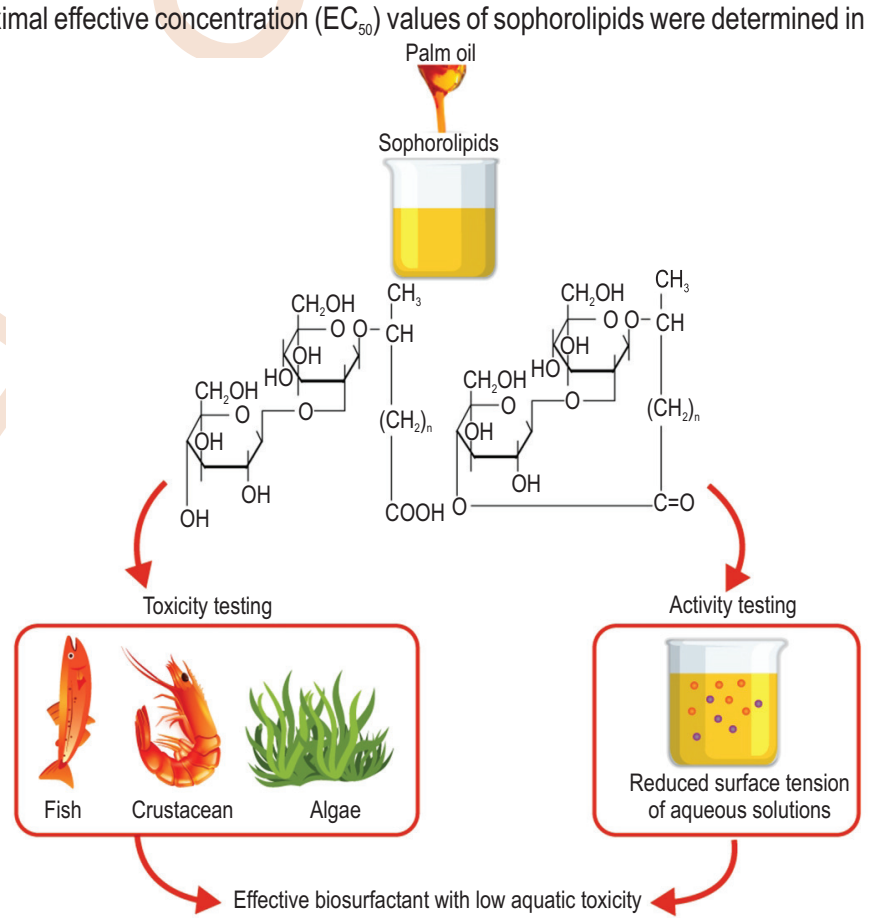
sophorolipids from S. bombicola are a promising biosurfactant with an ideal balance of low aquatic toxicity and high surface activity.

Key words: Aquatic toxicity, Biosurfactant, Sophorolipid, Surfactant

Reviewed by

Dr. S.K. Chakraborty

Dr. R.B. Raizada

How to cite : Kumano, W., K. Namakoshi, M. Araki, Y. Oda, A. Ueda, and Y. Hirata: Low toxicity and high surface activity of sophorolipids from Starmerella bombicola in aquatic species: A preliminary study. J. Environ. Biol., 40, 595-600 (2019). 


\section{Introduction}

Surface active agents or surfactants are amphiphilic compounds that lower surface and interfacial tensions, thereby making them useful as detergents or emulsifiers with a wide range of residential, commercial, medical laundering and sanitation (Scheibel, 2004), cosmetic (Falbe, 2012) and drug delivery (Torchilin, 2001) applications. However, given the ability of surfactant to reduce surface tension, they can also have significant toxicity towards aquatic life. Oya et al. (2007) reported that the surface tensions associated with half-maximal toxicity of several chemical surfactants ranged from $45 \mathrm{mN} \mathrm{m}^{-1}$ to $70 \mathrm{mN} \mathrm{m}^{-1}$, depending on the surfactant examined. Biosurfactants are surface-active amphiphilic compounds produced by microorganisms that contain both hydrophilic and hydrophobic regions that enable them to aggregate at the interfaces between fluids with different polarities, such as hydrocarbons and water, thereby decreasing the interfacial surface tension (Vijayakumar and Saravanan, 2015). Recently, there has been a growing interest in the identification and optimization of biosurfactants produced by yeast, bacteria and fungi from substrates such as sugar beet molasses (Onbasli and Aslim, 2008), oils (Kumar et al., 2014), waste (Santos et al., 2016) and other rhizospheric/phyloplanic sources (Tomar et al., 2013).

In addition to various classes of biosurfactants, such as glycolipids, lipoproteins, lipopeptides and phospholipids, produced by different micro-organisms, sophorolipids (Gorin et al., 1961) have recently become a focus of attention. Sophorolipids, along with rhamnolipids and trehalolipids, are classified as glycolipids (Jarvis and Johnson, 1949) and are known to occur as a mixture of lactonic and acidic molecules (Tulloch et al., 1968; Hu and Ju, 2001). Sophorolipids are lowfoaming biosurfactants that are readily biodegradable and have low levels of cytotoxicity (Hirata et al., 2009), thus making them potential candidates for laundering and bioremediation.

Production of sophorolipids by non-pathogenic yeast Starmerella bombicola has been the focus of many optimization efforts and has been examined using a variety of culture substrates, including carbohydrates, vegetable oils (such as sustainable palm oil), animal fat, whey, soy molasses and waste frying oil (Van Bogaert et al., 2007). Although, a large number of studies have been conducted on the production and molecular characterization of sophorolipids produced by S. bombicola (Shah et al., 2017; Van Renterghem et al., 2018; Li et al., 2016), however these compounds have not been extensively investigated as other glycolipids (De Graeve et al., 2018). Only few studies have examined the toxicity of these sophorolipids to aquatic life in conjunction with evaluation of their surfactant properties, which is of ecological significance.

Given that there is a trade-off relationship between the surface activity of a surfactant and aquatic toxicity, the present study was carried out to evaluate toxicity and surface activity of sophorolipids extracted from S. bombicola. Toxicity of these sophorolipids were assessed against three aquatic species,
Pseudokirchneriella subcapitata, an alga Oryzias latipes, a fish and Daphnia magna, a crustacean.

\section{Materials and Methods}

Preparation of sophorolipids from S. bombicola: Sophorolipids evaluated in this study were produced by $S$. bombicola ATCC22214 grown in a medium comprising $10 \%$ glucose, $8 \%$ palm oil [certified by the Roundtable on Sustainable Palm Oil (https://rspo.org/)], 0.8\% $\mathrm{KH}_{2} \mathrm{PO}_{4}, 0.2 \% \mathrm{MgSO}_{4}, 0.1 \%$ urea and $0.2 \%$ yeast extract. Sophorolipids were purified as described by Cooper and Paddock (1984). Briefly, a 3 I batch was fermented in a $5 \mathrm{I}$ jar fermenter. Fermentation was carried out for 12 days at $30^{\circ} \mathrm{C}$ and $600 \mathrm{rpm}$, with an air flow rate of $0.6 \mathrm{vvm}$. Sophorolipids were produced as a mixture of 1', 4"-lactone and free acid form in a ratio of approximately 7:3.

Preparation of hard water: Hard water for toxicity and surface tension tests was prepared in accordance with the AOAC International procedure for synthetic hard water (Beloian, 1995). Briefly, a $4 \mathrm{ml}$ of Solution II ( $56.03 \mathrm{~g} \mathrm{NaHCO}_{3}$ made up to 1 l with distilled water) was added to $1 \mathrm{ml}$ of Solution I $\left(67.71 \mathrm{~g} \mathrm{MgCl}_{2}\right.$. $6 \mathrm{H}_{2} \mathrm{O}$ and $73.99 \mathrm{~g}$ of $\mathrm{CaCl}_{2}$ made up to 1 I with distilled water). The volume was then made up to $100 \mathrm{ml}$ distilled water. This solution was prepared to have a hardness of 1000 ppm and was diluted with distilled water before use.

\section{Toxicity tests}

Algal growth inhibition test: $P$. subcapitata (ATCC No.: 22662) was maintained in media in accordance with the Organisation for Economic Co-operation and Development (OECD) guidelines for Freshwater Alga and Cyanobacteria, Growth Inhibition Test (2006). The algae were exposed to different concentrations of sophorolipids $\left(0,100,200,300,400\right.$ and $\left.500 \mathrm{mgl}^{-1}\right)$ for $72 \mathrm{hr}$, and thereafter algal biomass was determined using a hemocytometer. The $\mathrm{EC}_{50}\left(\mathrm{mg} \mathrm{l}^{-1}\right)$ of $P$. subcapitata was compared with the established reference data for determining the acute toxicity and genotoxicity of five selected anionic and nonionic surfactants described by Liwarska-Bizukojc (2005).

Fish toxicity test: 0 . latipes were obtained from the National Institute of Environmental Research (Environmental Research Complex, Incheon, Korea). They were bred in accordance with OECD guidelines for Fish, Acute Toxicity Test (1992) at $23 \pm 2^{\circ} \mathrm{C}$ under $16 \mathrm{hr}$ light and $8 \mathrm{hr}$ dark photoperiod, with illumination being provided by artificial lighting. Prior to the initiation of experimentation, fish without any visible gross abnormalities were selected and acclimated for 10 days. During the acclimation period, the water temperature and dissolved oxygen concentration were maintained at $21.6-23.2^{\circ} \mathrm{C}$ and $90.0 \%$ $105 \%$, respectively. Following acclimation, 10 fish were randomly selected and placed in a test chamber containing $3 \mathrm{I}$ of one of the six sophorolipid solutions in water $(0,100,200,300,400$ or 500 $\mathrm{mgl}^{-1}$ ) at $23 \pm 2^{\circ} \mathrm{C}$, with a dissolved oxygen level of at least $60 \%$, and $\mathrm{pH} 6.0-8.5$. Temperature and oxygen levels were maintained 


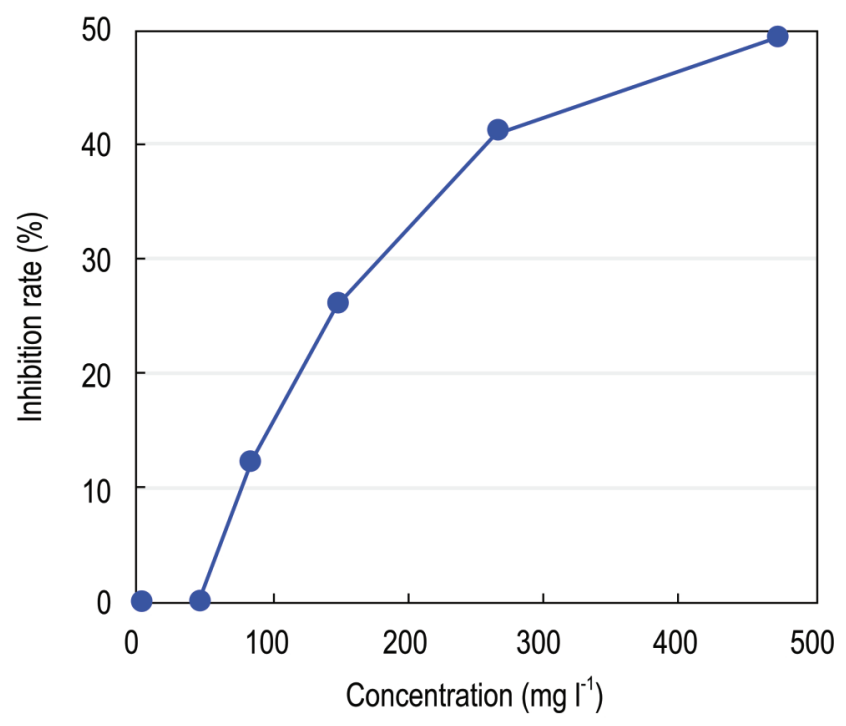

Fig. 1: Toxicity of sophorolipids on the growth of Pseudokirchneriella subcapitata: The algae were exposed to several different concentrations of sophorolipid and the resulting growth inhibition rates were calculated.

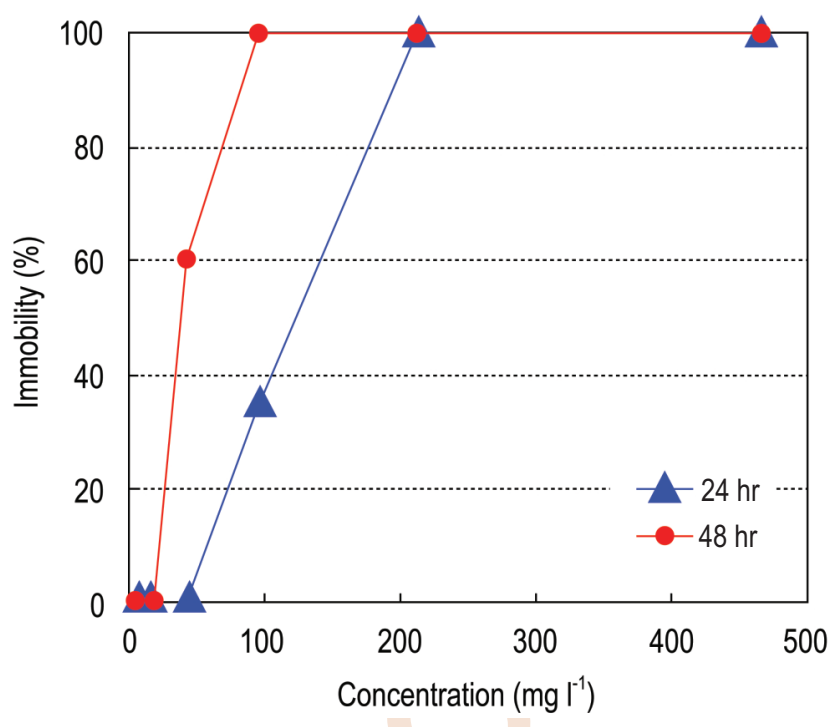

Fig. 3: Acute toxicity of sophorolipids towards Daphnia magna. The crustaceans were exposed to several different concentrations of sophorolipid and the resulting percentage mortalities were calculated.

at a constant level throughout the course of the exposure period. The room was artificially illuminated with fluorescent lighting on $16 \mathrm{hr}$ light and $8 \mathrm{hr}$ dark cycle. Fish were observed for abnormalities at 1, 3, 6, 24, 48, 72 and $96 \mathrm{hr}$ after the initiation of exposure. Upon discovery, any dead fish were removed from the chamber and mortalities were recorded.

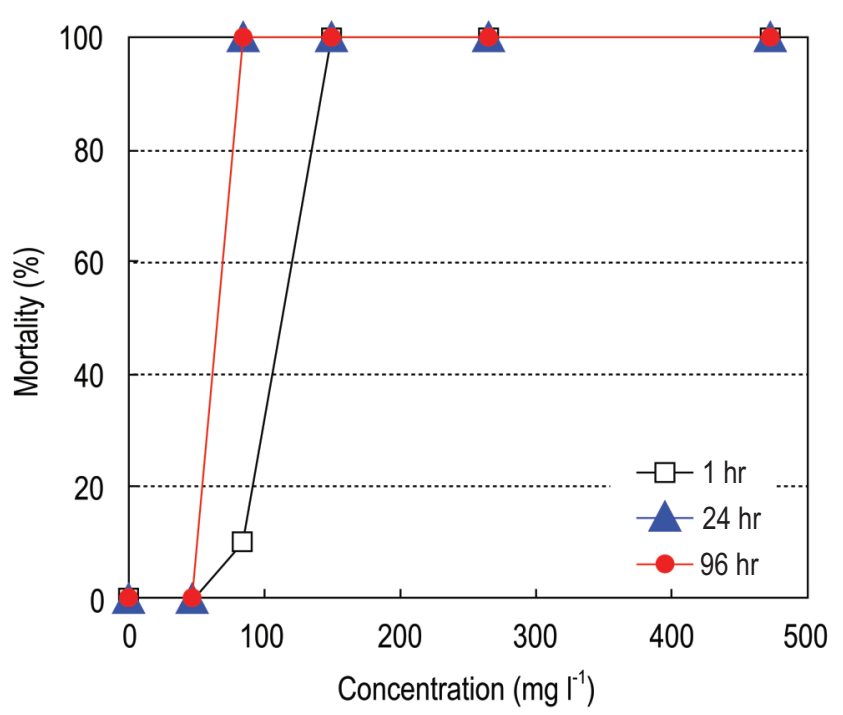

Fig. 2: Acute toxicity of sophorolipids towards Oryzias latipes. The fish were exposed to several different concentrations of sophorolipid and the resulting percentage mortalities were calculated.

Crustacean immobilization test: $D$. magna were obtained from the National Institute of Agricultural Science \& Technology (Gyeonggi-do, Korea) and treated in accordance with OECD guidelines for Daphnia sp. Acute Immobilisation Test (2004). Young daphnids, less than $24 \mathrm{hr}$ old, were obtained from mature (>14-days-old) third-generation daphnids and were placed in a culture beaker containing Elendt M4 medium, in which they were maintained for 28 days. The culture beaker was maintained at 20 $\pm 1^{\circ} \mathrm{C}$ in a water bath under $16 \mathrm{hr}$ light and $8 \mathrm{hr}$ dark cycle. After preparation, the $\mathrm{pH}$ and hardness of water were 7.69-7.86 and $250 \mathrm{mg} \mathrm{CaCO}_{3} \mathrm{I}^{-1}$, respectively.

During culture period, Daphnia were observed once daily for abnormal behavior, antennal movement, appearance, neonate production and ephippia. In addition, five daphnids were placed in $100 \mathrm{ml}$ of diluted sophorolipid solution $(0,100,200,300$, 400 or $\left.500 \mathrm{mg} \mathrm{l}^{-1}\right)$ contained in test dishes in a water bath $(20 \pm$ $1^{\circ} \mathrm{C}$ ), at a dissolved oxygen level of not less than $3 \mathrm{mg} \mathrm{l}^{-1}$ and $\mathrm{pH}$ 6-9, and exposed for 48-hr under a continuous $16 \mathrm{hr}$ light and $8 \mathrm{hr}$ dark cycle. During the exposure period, the daphnids remained fed, and at 24 and $48 \mathrm{hr}$ were observed for general appearance, behavior, swimming or immobilization and abnormalities. Immobilization was considered as no movement or movement of antennae (posterior abdomen), however, failure to float or swim for approximately $15 \mathrm{sec}$ after dishes had been gently shaken. Daphnids lying on their sides were considered to be immobile.

Surface tension measurements for determination of surface activity: Surface tension was measured as described by Hirata et al. (2009). Briefly, surface tension was measured at $20^{\circ} \mathrm{C}$ using a CBVP-Z Tensiometer (Kyowa Interface Science, Niiza City, 
Saitama, Japan) according to the method described by Wilhelmy (1863) using solutions of $\mathrm{pH} 7.0$ and the indicated water hardness and concentration of sophorolipids. This study was reviewed and approved by the IACUC of Biotoxtech Co., Ltd. based on the Animal Protection Act (Enactment May 31, 1991, No. 4379; Revision February 29, 2008, No. 8852) (Approval No.: 09765).

Statistical Analyses: One-way analysis of variance (ANOVA) was employed to analyze homogeneous data. If ANOVA results were significant, they were assessed using Dunnett's test for multiple comparisons. The trimmed Spearman-Karber method was used for estimating median lethal concentrations in toxicity bioassays, and the moving average-angle method was used to calculate $\mathrm{LD}_{50}$ values. Statistical analyses were performed using SAS software (version 9.1.3; SAS Institute Inc., Cary, NC, U.S.A.).

\section{Results and Discussion}

\section{Toxicity tests}

Toxicity of sophorolipids on the growth $P$. subcapitata: Unicellular alga, P. subcapitata is routinely used in chemical toxicity studies (Brezovšek et al., 2014; de Melo et al., 2013). To assess the toxicity of sophorolipids towards this species, the algae were exposed to several different concentrations of these glycolipids and the resulting growth inhibition rate was calculated. No observable effects on algal growth were detected at or below a sophorolipid concentration of $47.3 \mathrm{mg} \mathrm{l}^{-1}$ (Fig. 1) whereas exposure to a concentration of $83.7 \mathrm{mg} \mathrm{I}^{-1}$ resulted in a small degree $(12.4 \%)$ of growth inhibition. Increasing the concentration to $149 \mathrm{mg} \mathrm{l}^{-1}$ and $266 \mathrm{mg} \mathrm{l}^{-1}$ increased the growth inhibition to $26.1 \%$ and $41.2 \%$, respectively; however, even after $72 \mathrm{hr}$ of exposure to the highest concentration of sophorolipids tested (473 $\mathrm{mg} \mathrm{l}^{-1}$ ) inhibition of average specific growth rate remained below $50 \%$. This half-maximal effective concentration $\left(\mathrm{EC}_{50}\right)$ of $>473 \mathrm{mg} \mathrm{I}^{-1}$ is considerably higher than those reported by Liwarska-Bizukojc et al. (2005) for P. subcapitata inhibition by common chemical surfactants (Table 1). Indeed, the $\mathrm{EC}_{50}$ of sophorolipid was more than an order of magnitude higher than that of sodium dodecyl sulfate and alcohol ethoxylate, and more than four times higher than that of linear alkylbenzene sulfonate. These results indicate that compared to common chemical surfactants sophorolipids are biosurfactants with very low toxicity towards aquatic algae. The results of the current study are comparable with those previously reported for glycolipids, which were found to have high $\mathrm{EC}_{50}$ values for various algal species (Poremba et al., 1991; Invally et al., 2017; De Oliveira et al., 2017). Hence, it can be concluded that if sophorolipids exhibit low toxicity towards other organisms and result in effective surface tension at or below their $\mathrm{EC}_{50}$ concentrations, they would be an ideal biosurfactant for development and commercialization.

Acute toxicity of sophorolipids towards 0. latipes: To further investigate the potential applicability of sophorolipids as biosurfactants, the concentration-dependent effects of sophorolipids on the viability of Japanese rice fish, 0 . latipes were examined. Similar to $P$. subcapitata growth inhibition results, it was observed that sophorolipid concentrations up to $47.3 \mathrm{mg} \mathrm{l}^{-1}$ had no measurable effect on the viability of 0 . latipes, even after $96 \mathrm{hr}$ exposure (Fig. 2). The effects of sophorolipids on O. latipes viability were partially dependent on exposure time, increasing noticeably from $1-24 \mathrm{hr}$ whereas exposure for 24 - $96 \mathrm{hr}$ had no measurable effect on the viability of these fish. Plotting mortality rates after $96 \mathrm{hr}$ revealed that the median lethal concentration $\left(\mathrm{LC}_{50}\right)$ of sophorolipids towards this species was $64.8 \mathrm{mg} \mathrm{I}^{-1}$ (95\% confidence limits: $59.6-72.4 \mathrm{mg} \mathrm{l}^{-1}$ ). These results are broadly consistent with the findings of previous studies that had evaluated the toxicity of biosurfactants against various marine fish and recorded survival rates between $70 \%$ and $95 \%$ (Santos et al., 2017; Saeki et al., 2009).

Acute toxicity of sophorolipids towards $D$. magna: When toxicity of sophorolipids towards $D$. magna, a planktonic crustacean commonly used in ecotoxicology studies, was examined, no observable effects on swimming ability were detected at concentrations below $20.3 \mathrm{mg} \mathrm{l}^{-1}$. This result is more favorable compared with that obtained for rhamnolipid, the $\mathrm{LC}_{50}$ of which was found to be $13.8 \mathrm{mgl}^{-1}$ (SantaAnna et al., 2002), and for sophorolipids derived from Candida bombicola, the $\mathrm{LC}_{50}$ of which was $15 \mathrm{mg} \mathrm{l}^{-1}$ (Otto et al., 1999). At concentrations greater than

Table 1: Comparison of the toxicities of sophorolipds from Starmerella bombicola and anionic/nonionic surfactants toward Pseudokirchneriella subcapitata

\begin{tabular}{lll}
\hline Surfactant & $\mathrm{EC}_{50}\left(\mathrm{mgl}^{-1}\right)$ & Water Hardness (ppm) \\
\hline Sophorolipids & $>473(72 \mathrm{hr})$ & 24 \\
Sodium dodecyl sulfate & $37(72 \mathrm{hr})^{1}$ & $24^{1}$ \\
Linear alkylbenzene sulfonate & $112(72 \mathrm{hr})^{1}$ & $24^{1}$ \\
Alcohol ethoxylates & $7(72 \mathrm{hr})^{1}$ & $24^{1}$ \\
\hline
\end{tabular}

${ }^{1}$ These are the results of toxicity bioassays for $P$. subcapitatae xposed to selected anionic and nonionic surface-active agents reported by LiwarskaBizukojc et al. (2005) and performed in accordance with the OECD Guidelines for Testing of Chemicals, Sect. 2: Effects on Biotic Systems, No. 201 "Alga, Growth Inhibition Test." Adopted June 1984. Paris: OECD (1981). A revised version of the same OECD guidelines (2006) was followed in the present study for the algal toxicity test 
Table 2: Interfacial activity of sophorolipids at EC(LC)

\begin{tabular}{llll}
\hline & & Toxicity test & Surface tension test \\
\hline Species & Water hardness & $\begin{array}{l}\text { Measured EC }(\text { LC })_{50} \\
\text { of sophorolipids }\left(\mathbf{m g}^{-1}\right)\end{array}$ & $Y_{\text {tox }}$ \\
\hline Oryzias latipes & & 65 & 39 \\
Daphnia magna & $61 \mathrm{ppm}$ & 48 & 41 \\
\hline
\end{tabular}

The surface tension of aqueous solutions containing the indicated $\mathrm{EC}(\mathrm{LC})_{50}$ concentration of sophorolipids was measured using a tensiometer as described in the Materials and Methods section. The surface tension values presented in this table are averages of six independent measurements. $\mathrm{EC}(\mathrm{LC})_{50}=$ half-maximal (median lethal) concentration. ytox $=$ surface tension at $\mathrm{EC}(\mathrm{LC})_{50}$

$44.5 \mathrm{mg} \mathrm{l}^{-1}$, the effects of sophorolipids on $D$. magna swimming ability were found to be dependent on exposure time, increasing from 24 to $48 \mathrm{hr}$ of exposure (Fig. 3). Quantification and graphical plotting of inhibition of $D$. magna swimming in response to a range of sophorolipid concentrations revealed that after exposure to sophorolipids for $48 \mathrm{hr}$, the $\mathrm{EC}_{50}$ was $48.2 \mathrm{mg} \mathrm{l}^{-1}$ (95\% confidence limits: $40.6-57.2 \mathrm{mg} \mathrm{l}^{-1}$ ), which was similar to the $\mathrm{LC}_{50}$ observed after 24 and $96 \mathrm{hr}$ in 0 . latipes mortality test (Fig. 2). Taken together, the results of algal growth, crustacean mortality and fish immobility bioassays enabled identification of a range of concentrations at which sophorolipids exhibit low toxicity towards several aquatic species. Nevertheless, higher sophorolipid toxicity was detected in the crustacean mortality test compared with the algal growth test, and there was a small additional increase in toxicity in fish immobility test. These findings are probably related, at least in part, to the species used and nature of each toxicity test.

Surface activities of sophorolipids at EC(LC) $)_{50}$ : In the present study, we determined the surface tension of aqueous solutions of sophorolipids at median toxicity values (toxic surface tension, or $\mathrm{Y}_{\text {tox }}$ ). As water hardness is known to affect both interfacial activity and toxicity of surfactants, a surface tension test was performed using the same water hardness conditions that were used for the toxicity tests, the results of which are summarized in Table 2. At $\mathrm{LC}_{50}$ towards 0 . latipes $\left(65 \mathrm{mg} \mathrm{l}^{-1}\right)$, sophorolipids reduced the surface tension of aqueous solution to $39 \mathrm{mN} \mathrm{m}^{-1}$. Similarly, at $\mathrm{EC}_{50}$ towards $D$. magna $\left(48 \mathrm{mg} \mathrm{l}^{-1}\right)$, sophorolipids reduced the surface tension to $41 \mathrm{mN} \mathrm{m}^{-1}$. Although the aquatic species, water hardness and median toxicity concentration of sophorolipids differed between these two toxicity tests, the $\gamma_{\text {tox }}$ remained unchanged. Moreover, these $\gamma_{\text {tox }}$ values for sophorolipids were lower than any of the $\gamma_{\text {tox }}$ values reported for chemical surfactants in 0 . latipes and $D$. magna toxicity studies conducted by Oya et al. (2007). Furthermore, the results obtained in the present study are more favorable compared with the previously reported surface tensions of $32.1-34.2 \mathrm{mN} \mathrm{m}^{-1}$ for sophorolipids (Develter et al., 2010) and $37 \mathrm{mN} \mathrm{m}^{-1}$ for rhamnolipids (Cheng et al., 2017).

The purpose of this research work was to gain insights into the efficacy of sophorolipids which have potential utility as environmental friendly low-toxicity biosurfactants. The data obtained in the current study indicate that sophorolipids have low aquatic toxicity and good interfacial activity, thus satisfying two important criteria for an ideal surfactant. Herein, it is demonstrated that sophorolipid biosurfactant produced using sustainable palm oil as a carbon source is an effective surfactant at its $\mathrm{EC}(\mathrm{LC})_{50}$, possibly even more so than the commonly used chemical surfactants. Hence, the current findings have significant implications for global laundering, sanitization and environmental remediation applications. This study sets a precedent for the evaluation of other biosurfactants that may possess a similarly desirable profile of efficacy versus toxicity.

\section{Acknowledgment}

Editorial support, in the form of writing based on authors' detailed directions, collating author comments, copyediting, fact checking, and referencing, was provided by Cactus Communications.

\section{References}

Beloian, A.: AOAC official method 960.09: Germicidal and detergent sanitizing action of disinfectants. In: Official methods of analysis of AOAC International (Ed.: P. A. Cunniff). 16 ${ }^{\text {th }}$ Edn., AOAC International, Arlington (1995).

Brezovšek, P., T. Eleršek and M. Filipič: Toxicities of four anti-neoplastic drugs and their binary mixtures tested on the green alga Pseudokirchneriella subcapitata and the cyanobacterium Synechococcus leopoliensis. Water Res., 52, 68-177 (2014).

Bagnolo, G.: An overview of the technology and market for surfactants from renewable resources. Compen. Deter. Supple. Household Perso. Care Tod., 6, 2, 12-14 (2011).

Cooper, D.G. and D.A. Paddock: Production of a biosurfactant from Torulopsis bombicola. Appl. Environ. Microbiol., 47, 173-176 (1984).

Cheng, T., J. Liang, J. He, X. Hu, Z. Ge and J. Liu: A novel rhamnolipidproducing Pseudomonas aeruginosa ZS1 isolate derived from petroleum sludge suitable for bioremediation. AMB Express, 7, 120 (2017).

De Graeve, M., S.L. De Maeseneire, S.L. Roelants and W. Soetaert: Starmerella bombicola, an industrially relevant, yet fundamentally underexplored yeast. FEMS Yeast Res., 18, foy072 (2018).

De Melo, E.D., A.H. Mounteer, L.H. de Souza Leão, R.C.B. Bahia and I.M.F. Campos: Toxicity identification evaluation of cosmetics industry wastewater. J. Hazard. Mater., 244, 329-334 (2013).

De Oliveira, D.W., A.B. Cara, M. Lechuga-Villena, M. García-Román, V.M. Melo, L.R. Gonçalves and D.A. Vaz: Aquatic toxicity and 
biodegradability of a surfactant produced by Bacillus subtilis ICA56. J. Environ. Sci. HIth. A Tox. Hazard. Subst. Environ. Eng., 52, 174-181 (2017).

Develter, D.W. and L.M. Lauryssen: Properties and industrial applications of sophorolipids. Eur. J. Lipid Sci. Technol., 112, 628638 (2010).

Falbe, J.: Surfactants in consumer products: In: Theory, Technology and Application. Springer Science \& Business Media, Heidelberg, Germany (2012).

Gorin, P.A.J., J.F.T. Spencer and A.P. Tulloch: Hydroxy fatty acid glycosides sophorose from Torulopsis magnoliae. Can. J. Chem., 39, 846-855 (1961).

Hirata, Y., M. Ryu, Y. Oda, K. Igarashi, A. Nagatsuka, T. Furuta and M. Sugiura: Novel characteristics of sophorolipids, yeast glycolipid biosurfactants, as biodegradable low-foaming surfactants. J. Biosci. Bioeng., 108, 142-146 (2009).

$\mathrm{Hu}$, Y. and L.K. Ju: Purification of lactonic sophorolipids by crystallization. J. Biotechnol., 87, 263-272 (2001).

Invally, K. and L.K. Ju: Biolytic Effect of rhamnolipid biosurfactant and dodecyl sulfate against phagotrophic alga Ochromonas danica. J. Surfactants Deterg., 20, 1161-1171 (2017).

Jarvis, F.G. and M.J. Johnson: A glycolipid produced by Pseudomonas aeruginosa. J.Am. Chem. Soc., 71, 4124-4126 (1949).

Kumar, G., R. Kumar and A. Sharma: Characterization of biosurfactants from indigenous soil bacteria recovered from oil contaminated sites. J. Environ. Biol., 36, 1101-1104 (2015).

Li, J., H. Li, W. Li, C. Xia and X. Song: Identification and characterization of a flavin-containing monooxygenase MoA and its function in a specific sophorolipid molecule metabolism in Starmerella bombicola. Appl. Microbiol. Biotechnol., 100, 1307-1318. (2016)

Liwarska-Bizukojc, E., K. Miksch, A. Malachowska-Jutsz and J. Kalka: Acute toxicity and genotoxicity of five selected anionic and nonionic surfactants. Chemosphere, 58, 1249-1253 (2005).

OECD (2004), Test No. 202: Daphnia sp. Acute Immobilisation Test, OECD Guidelines for the Testing of Chemicals, Section 2, OECD Publishing, Paris, https://doi.org/10.1787/9789264069947-en

OECD (1992), Test No. 203: Fish, Acute Toxicity Test, OECD Guidelines for the Testing of Chemicals, Section 2, OECD Publishing, Paris, https://doi.org/10.1787/9789264069961-en

OECD (2006), Test No. 201: Freshwater Alga and Cyanobacteria, Growth Inhibition Test, OECD Guidelines for the Testing of Chemicals, Section 2, OECD Publishing, Paris, https://dx.doi.org/10.1787/9789264069923-en

Onbasli, D. and B. Aslim: Biosurfactant production in sugar beet molasses by some Pseudomonas spp. J. Environ. Biol., 30, 161163 (2009).

Otto, R.T., H.J. Daniel, G. Pekin, K. Müller-Decker, G. Fürstenberger, M. Reuss and C. Syldatk: Production of sophorolipids from whey. Appl. Microbiol. Biotechnol., 52, 495-501 (1999).

Oya, M., S. Orito, Y. Ishikawa and T. lizuka: Effects of water hardness and existence of adsorbent on toxic surface tension of surfactants for aquatic species. J. Oleo. Sci, 56, 237-243 (2007).

Poremba, K., W. Gunkel, S. Lang and F. Wagner: Marine biosurfactants, III. Toxicity testing with marine microorganisms and comparison with synthetic surfactants. Zeitschrift für Naturforschung C, 46, 210-2161 (1991).

Saeki, H., M. Sasaki, K. Komatsu, A. Miura and H. Matsuda: Oil spill remediation by using the remediation agent JE1058BS that contains a biosurfactant produced by Gordonia sp. strain JE-1058. Bioresour. Technol., 100, 572-577 (2009).

Santa Anna, L.M., G.V. Sebastian, E.P. Menezes, T.L.M. Alves, A.S. Santos, N. Pereira Jr. and D.M.G. Freire: Production of biosurfactants from Pseudomonas aeruginosa PA 1 isolated in oil environments. Braz. J. Chem. Eng., 19, 159-166 (2002).

Santos, D.K., A.H. Resende, D.G. de Almeida, R.D.C.F. Soares da Silva, R.D. Rufino, J.M. Luna, I.M. Banat and L.A. Sarubbo: Candida lipolytica UCP0988 biosurfactant: Potential as a bioremediation agent and in formulating a commercial related product. Front. Microbiol., 8, 767 (2017).

Santos, D.K.F., R.D. Rufino, J.M. Luna, V.A. Santos and L.A. Sarubbo: Biosurfactants: Multifunctional biomolecules of the $21^{\text {st }}$ century. Int. J. Mol. Sci., 17, 401 (2016).

Scheibel, J.J.: The evolution of anionic surfactant technology to meet the requirements of the laundry detergent industry. J. Surfactants Deterg., 7, 319-328 (2004).

Shah, M.U.H., M. Sivapragasam, M. Moniruzzaman, M.M.R. Talukder, S.B. Yusup and M. Goto: Production of sophorolipids by Starmerella bombicola yeast using new hydrophobic substrates. Biochem. Eng. J., 127, 60-67 (2017).

Tomar, S., B.P. Singh, M. Lal, M.A. Khan, T. Hussain, S. Sharma, S.K. Kaushik and S. Kumar: Screening of novel microorganisms for biosurfactant and biocontrol activity against Phytophthora infestans. J. Environ. Biol., 35, 893-899 (2014).

Torchilin, V.P.: Structure and design of polymeric surfactant-based drug delivery systems. J. Control. Release., 73, 137-172 (2001).

Tulloch, A.P., A. Hill and J.F.T. Spencer: Structure and reactions of lactonic and acidic sophorosides of 17-hydroxyoctadecanoic acid. Can. J. Chem., 46, 3337-3351 (1968).

Van Bogaert, I.N.A., K. Saerens, C. De Muynck, D. Develter, W. Soetaert and E.J. Vandamme: Microbial production and application of sophorolipids. Appl. Microbiol. Biotechnol., 76, 23-34 (2007).

Van Renterghem, L., S.L. Roelants, N. Baccile, K. Uyttersprot, M.C. Taelman, B. Everaert, S. Mincke, S. Ledegen, S. Debrouwer, K. Scholtens and C. Stevens: From lab to market: An integrated bioprocess design approach for new-to-nature biosurfactants produced by Starmerella bombicola. Biotechnol. Bioeng., 115, 1195-1206 (2018).

Vijayakumar, S. and V. Saravanan: Biosurfactants-Types, Sources and Applications. Res. J. Microbiol., 10,181-192 (2015).

Wilhelmy, L.: Uber die Abhanigkeit der Capillaritats-Constanten des Alkols von Substanz und Gestalt des benetzten festen Korpers. Ann. Physik. Lpz., 119, 177-217 (1863). 